\title{
LANGUAGE TRANSFER AND UNIVERSAL GRAMMATICAL RELATIONS
}

\author{
Susan Gass ${ }^{1}$ \\ The University of Michigan
}

It is generally accepted by both theoreticians and language teachers that when attempting to communicate in a second language, learners often "transfer" elements of their native language onto the speech patterns of the target language. Despite the wide recognition of this phenomenon and the important role it has had in language learning and pedagogical search, its true nature has not been adequately established. In oner to better determine the nature of language transfer, a study investigating the acquisition of relative clauses by adult second language learners was conducted. The purposes of this study were to determine what language transfer consists of, what language phenomena are and are not transferred, what constitutes evidence for the existence of transfer and what the role in language transfer of language universals is. It was found that an adequate description of language transfer cannot be given without a consideration of target lan. guage facts and language universals. On the basis of these results a model of language transfer is proposed that predicts under which conditions transfer is most likely to occur. The model sug. gested herein includes notions of language universals, language distance and surface language phenomena.

\section{Introduction}

It is generally recognized by both theoreticians and language teachers that when attempting to communicate in a second lan. guage, second language learners often "transfer" elements of their native language (NL) onto the speech patterns of the target language (TL). Despite the wide recognition of this phenomenon and the important role it has had in language learning and pedagogical research, its true nature has not been adequately established. Recent debate has largely centered around the putative existence of transfer as an important variable in second language learning (Dulay and Burt 1974, 1975; Richards 1975; George 1972;

${ }^{1}$ This paper is based on my Indiana University $1979 \mathrm{Ph} . \mathrm{D}$. dissertation. I would like to express my appreciation to Josh Ard and in particular to Larry Selinker for helpful comments on earlier drafts of this paper. 
Schachter 1974), overlooking the more crucial questions of 1) what "language transfer" 2 consists of, 2) what language phenomena are and are not transferred, and 3) what constitutes evidence for the existence of transfer.

In fact, recent research has primarily dealt with transfer quantitatively. For example, George (1972) claimed that onethird of the errors in his corpus could be accounted for by means of native language interference, while Dulay and Burt (1975) re-. ported that less than $5 \%$ of the errors found in their corpus could be attributed to patterns in the native languages of their subjects. However, in attempting to understand the phenomenon of language transfer, it is our working hypothesis that in order to quantify transfer, it is first necessary to determine what types of language phenomena are generally transferable. This study is an attempt to deal with these background fundamental issues.

The concept of transfer was until recently a primary concern of scholars in the area of second language learning and pedagogy. In essence, transfer, a traditional term from the psychology of learning, is considered as the imposition of previously learned patterns onto a new learning situation. In its broadest interpretation, it is claimed that "the learning of task A will affect the subsequent learning of task B" (Jakobovits 1970:188). As a working definition, language transfer ${ }^{3}$ is here considered as a subset of this móre general process, incorporating the view that patterns of the NL (of all levels of linguistic structure), including both forms and functions of elements are superimposed on the patterns learned in a second language.

A theory of language pedagogy relating to this claim is the contrastive analysis hypothesis which has been divided into a weak

${ }^{2}$ For a tracing of the terms transfer and language transfer, see Selinker (1966:6, fn. 3) and James (1977:7ff.).

${ }^{3}$ It is an interesting and important question to consider whether language transfer is coextensive with transfer (in language). Are there phenomena in language learning which would fit the criteria of transfer (in language) but which would not fit the criteria of language transfer? For example, if a learner generalized on a pattern of his/her native language, to form an ungrammatical target language pattern, do we then have transfer, but not language transfer? In the example given, the end result in the learner's interlanguage is not a pattern mirroring the native language or the target language, but rather is an extension of a native language pattern. Whether or not this is possible is an empirical question; yet, it is an important issue which is frequently overlooked. 
and a strong form (see e.g. Wardhaugh 1970). In the "weak version", the concept is a tool used to account for the errors which actually occur without an attempt to predict what those actually occurring errors will be. Therefore, language transfer in this view is considered as a means of 'explaining' (or, more accurately justifying in the researcher's eye) a learner's errors. As such, it can hardly be considered a scientific claim, since it makes no predictions, thus rendering it unfalsifiable. On the other hand, within the "strong version", language transfer is a basis for predicting which patterns of the TL will be learned most readily and which will prove most troublesome. Therefore, it is claimed that 1) one can compare two languages to determine similarities and differences in structure and 2) similarities are easily learned, while differences result in a greater number of errors. Both claims have independently been challenged (see in particular Gradman 1970, 1971).

Attempting to deal with the claims made by contrastive analysis as theoretical claims, Selinker (1969:67) stated that "questions ... as to what language transfer consists of, what actually is transferred, how language transfer occurs, and what types of language transfer occur have not been adequately treated in a scientific manner". The intent of the present study is to further our knowledge in these areas in two important ways: 1) to extend this list of key questions to include a consideration of the role of universals of grammatical relations in this process and 2) to attempt to bring empirical evidence to bear on these fundamental researchable questions.

In dealing with these questions, we have limited the scope of this investigation to language transfer on one linguistic level: syntax. We have further limited it to one syntactic construction that of relative clauses. Despite the limitations of this study, it is hoped that the results obtained herein can be applied to the more general concept of language transfer.

\section{Relative Clause Formation Strategies}

Of import to the present discussion of relative clauses (RC) is the work on universals of relative clause formation (RCF) by Keenan and Comrie (1977) and Comrie and Keenan (1979). In their works they -argue that the re exists a universal hierarchy of grammatical relations out of which relativization can take place. Given below is the accessibility hierarchy (AH) which they proposed to reflect this. 


$$
\text { SU }>\text { DO }>\text { IO }>\text { OBL }>\text { GEN }>\text { OCOMP4 }
$$

According to the interpretation of this hierarchy, if in a given language, a RC can be formed with the relativizable noun phrase in some grammatical relation $g$, then it is also true in that language that RC's can be formed on NP's bearing any grammatical relation listed to the left of that particular one (i.e. higher on the hierarchy). An additional constraint is that RCF strategies must operate on adjacent segments of the hierarchy. What differentiates languages of the world is the lowest position which may be relativized.

In addition to the positions which languages may relativize, the world's languages differ in their RCF strategies in other significant ways. Some of the most important are: 1) adjacency to the head noun, 2) retention or omission of the relative clause marker, 3) ordering of the RC with respect to the head noun, 4) case markings on the relative market (variable vs. invariable) and 5) pronoun retention or omission. These variables will be explained more fully and dealt with in the discussion of the rhethodology of the present study.

In the area of RC's, seemingly contradictory evidence as to whether or not language transfer is present to any significant

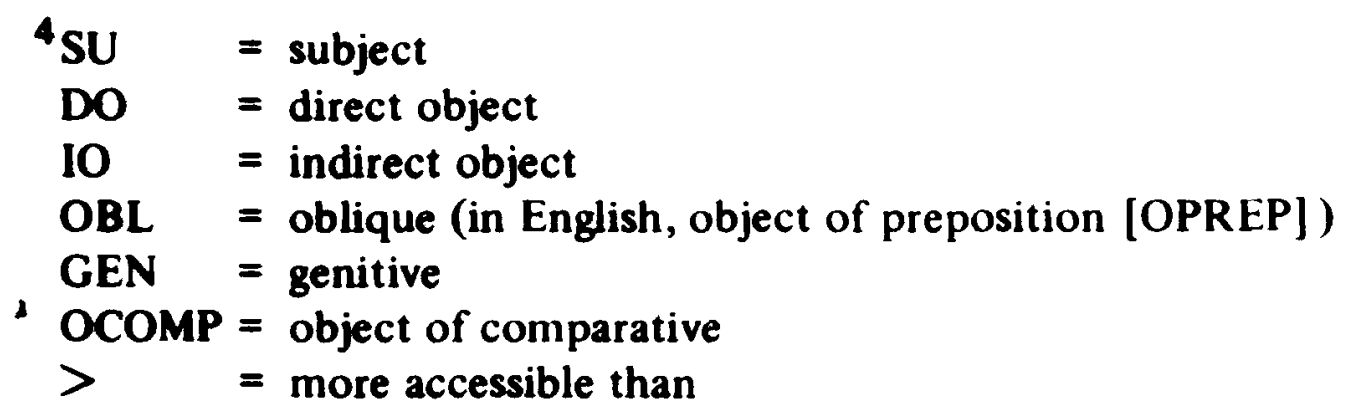

Relative Clouse Types
a. Subject
The dog that bit the man....
b. Direct Object
The man that the dog bit....
c. Indirect Object
The girl that I wrote a letter to. . .
d. Object of Preposition
The house that I talked to you about....
e. Genitive
The family whose house I like... .
f. Object of Comparative
The woman that I am taller than.... 
degree has been presented. Cook (1973) tested comprehension of English RC's by adults of heterogeneous NL backgrounds, comparing the results obtained with comparable results from children learning English as their first language. Although she did not address the issue of transfer directly, it may be inferred that there was little native language effect for the adults, since the errors which they made were similar to those made by children. A similar conclusion was reported by loup and Kruse (1977) who elicited grammaticality judgments of English RC' from adult speakers of typologically diverse language backgrounds. Their results showed no significant differences between the language groups, suggesting again no effects from the NL. However, Schachter (1974) claimed that one could indeed isolate one language group from another by means of the use of or lack of use of RC's. According to her analysis, one's NL does play an active role in L2 acquisition in the form of avoidance. Yet, despite these differing conclusions, it is important to keep in mind that they are based on data collected using diverse methods of elicitation. We must therefore question whether the results of studies using different elicitation methods are truly comparable (are true replications) or whether the comparison is a non-parallel one.

\section{Evidence for Language Transfer}

Following Selinker (1966: 103), an operational definition of language transfer can be given as a "process occurring from the native to the foreign language if frequency analysis shows that a statistically significant trend in the speaker's native language . . . is then paralleled by a significant trend toward the 'same' alternative in the speaker's attempted production of the foreign language sentences, phonetic features, phonetic sequences, etc." In the present study languages were classified as to whether or not they exhibited a particular RC variable. If the subjects of one of these groups differed in a statistically significant way from the other with regard to their use of or lack of use of the particular variable in English and if this difference reflected a NL pattern, there was considered to be evidence of language transfer. Referring to the variables given above, consider 5 , pronoun retention or omission. Chinese, Arabic and Persian retain pronouns in direct object relatives, while the other languages of this study, as well as English, do not. Therefore, if Chinese, Arabic and Persian subjects retained pronouns in English in that position to a significantly greater 
degree than the other subjects, language transfer was hypothesized to be present.

\section{Method}

Data on English RC's were gathered from 17 high intermediate and advanced adult $L 2$ learners enrolled in an 'English language training program at Indiana University. The nine native languages of these learners were: Arabic, Chinese, French, Italian, Korean, Persian, Portuguese, Japanese and Thai. In an attempt to determine whether different tasks given to the same person would yield different or even contradictory results, each subject was asked to perform two tasks. ${ }^{5}$ One was intended to provide information regarding a learner's receptive knowledge of English RC's and the other to elicit information regarding his/her productive knowledge of the same syntactic structure.

The first task to be discussed involved subjects' giving acceptability judgments to 29 English sentences, each of which contained a restrictive $\mathrm{RC}$. Of these sentences, 13 were well-formed English sentences and 16 were not. ${ }^{6}$ The ungrammatical sentences each contained only one of the four error types given below.

1. relative clause marker omission example: *The man walked to the store is my friend.

2. pronoun retention

example: *The woman that I sent a letter to her is my sister.

3. relative clause marker selection

example: *I left my book in an office who was locked.

4. adjacency

example: *The children were happy that I gave ice cream to.

Lexically, the sentences were kept as simple as possible to ensure that the judgments made were not made on the basis of something other than that which was specifically being tested.

The second task involved combining two sentences. It will be recalled that we wanted to gather data which would reflect two

${ }^{5}$ The study reported on in this paper formed part of a larger study in which three tasks were given to the subjects. The results of the third task, free compositions, are discussed in Gass (1979a).

${ }^{6}$ The basis for judgment was the native speaker intuition of the researcher with $96 \%$ agreement on the part of four other native speakers. 
aspects of linguistic knowledge: receptive and productive. To elicit a sufficient quantity of data of the second type, it was felt essential to 'force' subjects to produce sentences containing RC's. It was hoped that the results from this task would reflect a speaker's actual competence, since there were specific instructions to produce a particular structure. On the other hand, the results from the grammaticality judgment task (GJ) may not reflect the totality of the learner's knowledge, since the input was controlled to a greater degree by the researcher. It is in this respect that the results obtained from these two tasks are qualitatively different.

In this second task subjects were given 12 pairs of English sentences with specific instructions (oral and written) as to the way they should be combined. That is, the instructions were such that the only correct way of combining them would yield a RC. To test principles of universality of RCF sentences representing the 12 types given below were included. The first symbol represents the grammatical position in the first sentence of the noun which is identical in both sentences, and the second the grammatical relation of the NP in the subordinate sentence.

\section{SU SU}

2. SU DO

3. SU

4. SU

5. SU

6. SU

7. DO

8. DO

9. DO

10. DO

11. DO

12. DO example: The girl tan home. The girl was crying.

The girl who was crying ran home.

example: The girl ran home. I saw the girl.

The girl that I saw ran home.

As an example, consider (9), DO IO. The NP which is identical in those two sentences is in direct object position in the matrix sentence and an indirect object in the sentence to be embedded. 
Errors made on the sentence combining (SC) task were classified according to error type. These categories of errors were based on the differentiating parameters of the world's languages as given on p.330. However, not all of these error types were submitted to statistical analysis for one of two reasons: 1) some of the error types were very infrequent in the corpus or 2) the language under investigation could not be adequately partitioned along these parameters. The categories of a) adjacency, b) retention or omission of the RC marker and c) ordering of the relative clause with respect to the head noun were eliminated after failing on one or both of these criteria. Other errors, such as subject verb agreement, tense formation, spelling etc., were excluded from consideration since they were not relevant to the subject matter of this study.

Both of the tasks discussed above were given to each subject six times over a four month period. The lexical items differed but the syntactic structure was held constant from one testing session to another. Since statistical tests failed to detect significant difference among the testing sessions, the results discussed below are based on the total score across all of a subject's tests.

\section{Results and Discussion}

For all of the variables under consideration, group differences were tested by means of one-tailed $t$ tests. Groups were formed on the basis of presence versus absence of a particular variable in the NL of the subjects. The relevant parameters are presented in Table 1. As is evident from Table 2, not all of the variables considered on the GJ task exhibited evidence of transfer. In fact, the only variable for which transfer effects were discerned was that of pronoun retention and, then, only for the three highest positions on the $\mathbf{A H}$. Speakers of languages with pronoun retention in those positions are, therefore, more likely to accept ungrammatical sentences in English with pronominal copies than speakers of languages without pronominal reflexes in those positions. On the other hand, for relativization in genitive and object of comparative positions, no significant differences were found between the two groups, suggesting that language transfer is not a relevant notion for those positions. Yet, we must take into account the complexity of the patterns in question. Keenan and Comrie (1977) claim that pronoun retention is more common in lower positions on the AH than in the higher ones, such as subject or direct object. Hence, the acceptance of pronouns in genitive and object of comparative positions may be suggestive of a strategy used by L2 learners 
$\frac{8}{8}$
$\frac{8}{2}$

5 $\begin{aligned} & \text { 5 } \\ & 0\end{aligned}$

产

$x \times x x$

$x \times x$

홍

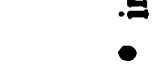

总产总

骨 营

总

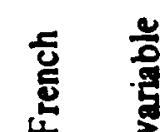

章 曾

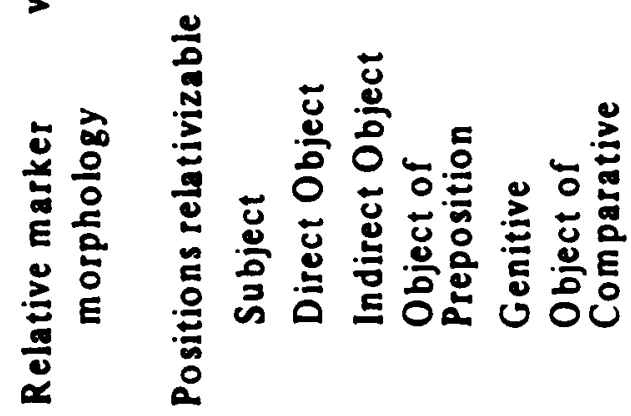

$x \times x \times$

$x \times x$

$x \times x \times x$

$x \times x \times$

$x \times x \times$

$x \times x \times$

$x \times x \times x$

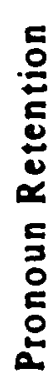

各

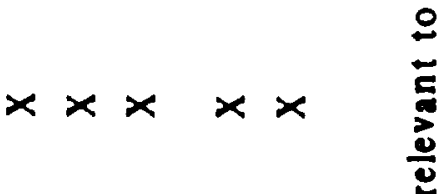

$\stackrel{5}{0}$

$\stackrel{\Xi}{\Xi}$

잉

$\check{8}$

:

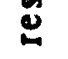

$\vdots$

3

층

$\div$.

$\div$

동

늠

$\cong 0$

¿

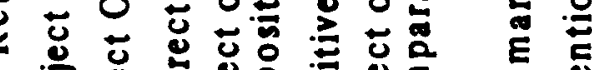

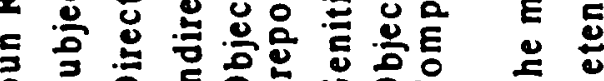

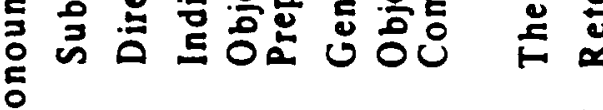


TABLE 2

A COMPARISON OF SIX VARIABLES WITH REGARD TO

TRANSFER ON THE GRAMMATICALITY JUDGMENT TASK

\begin{tabular}{|c|c|c|c|c|c|c|c|}
\hline Variable & & $\overline{\mathbf{x}}$ & sd & $\mathbf{F}$ & probability & values & probability* \\
\hline $\begin{array}{l}\text { Pronoun } \\
\text { retention } \\
\text { subject }\end{array}$ & $\begin{array}{l}\text { Group 1** } \\
\text { Group 2**}\end{array}$ & $\begin{array}{l}44.58 \\
11.85\end{array}$ & $\begin{array}{r}38.5 \\
15.8\end{array}$ & 5.92 & .01 & 2.24 & .026 \\
\hline $\begin{array}{l}\text { Pronoun } \\
\text { retention } \\
\text { DO }\end{array}$ & $\begin{array}{l}\text { Group 1** } \\
\text { Group 2** }\end{array}$ & $\begin{array}{l}77.5 \\
30\end{array}$ & $\begin{array}{l}28.2 \\
33.3\end{array}$ & 1.4 & ns & 3.15 & .004 \\
\hline $\begin{array}{l}\text { Pronoun } \\
\text { retention } \\
10\end{array}$ & $\begin{array}{l}\text { Group } 1 * * \\
\text { Group 2**}\end{array}$ & $\begin{array}{l}80 \\
31.85\end{array}$ & $\begin{array}{l}32.9 \\
29.6\end{array}$ & 1.24 & ns & 3.17 & .003 \\
\hline $\begin{array}{l}\text { Pronoun } \\
\text { retention } \\
\text { genitive }\end{array}$ & $\begin{array}{l}\text { Group 1** } \\
\text { Group 2** }\end{array}$ & $\begin{array}{l}47.29 \\
32.41\end{array}$ & $\begin{array}{l}25.04 \\
23.11\end{array}$ & 1.17 & ns & i. 27 & ns \\
\hline $\begin{array}{l}\text { Pronoun } \\
\text { retention } \\
\text { OComp }\end{array}$ & $\begin{array}{l}\text { Group 1** } \\
\text { Group 2*** }\end{array}$ & $\begin{array}{l}59 \\
37.62\end{array}$ & $\begin{array}{l}31.6 \\
39.7\end{array}$ & 1.57 & ns & 1.24 & ns \\
\hline Morpholo & $\begin{array}{l}\text { Group 1*** } \\
\text { Group 2*** }\end{array}$ & $\begin{array}{l}20.49 \\
36.46\end{array}$ & $\begin{array}{l}14.6 \\
26.09\end{array}$ & 3.18 & ns & .1 .56 & ns \\
\hline
\end{tabular}

"one-tailed test of significance

**Group 1 = speakers of languages with pronoun retention

Group 2 = speakers of languages without pronoun retention

**Group 1 = speakers of languages with an invariable marker

Group 2 = speakers of languages with a variable marker 
(independent of language background) in comprehending complex structures. This coincides with the results of the 1977 study by loup and Kruse. At this point it is not possible to determine whether the speakers of languages with pronoun retention in the lower positions are relying on the patterns of their own NL's or whether they, like speakers of languages without pronoun copies in RC's, are relying on natural orderings of difficulty.

Another differentiating factor among languages of the world is the variability of the RC marker. To determine the existence of language transfer in this area, two groups were tested: one was comprised of speakers of languages with a variable marker and the other of speakers of languages with an invariable marker. No significant differences were noted with regard to errors in English morphology, suggesting that marker variability is not a relevant factor in the prediction of difficulty in adult $\mathbf{L} 2$ acquisition.

In Table 3 are given the results of $t$ tests on the variables used for the sentence combining task. It can be seen that while the results are similar to those just discussed, they are not identical. Again, there are significant differences in the upper portions of the hierarchy (with the exception of subject position) and none in the two lowest positions. The difference in responses between the GJ task and the SC task on the variable of pronoun retention in subject position is particularly interesting in light of the fact that none of the languages under consideraiton has pronoun retention in that position. On the GJ task, a decoding task, there are presumably two steps taken on the road to acceptance or rejection of a sentence. It seems reasonable to assume that a subject first attempts to interpret the sentence since it is unlikely that it will be viewed as acceptable if it cannot be given some semantic interpretation. Secondly, the subject must determine whether or not it fits the pattern of English represented by his/her own interlanguage. Any decision of pattern congruity must be determined, at least in part, by familiarity. Clearly, speakers of languages which have pronominal reflexes in some positions are more familiar with that pattern than speakers without pronoun copies in any of the positions. Given this familiarity, it is likely that an extension of that pattern into a novel environment will be accepted. A plausible explanation is that this too is an instance of transfer, since it is best described in terms of rule generalization based on a NL pattern. However, considering the distinction between transfer (in language) and language transfer discussed in $\mathrm{fn} .3$, we have a case here of transfer, but not language transfer, since the pattern in question does not exist in the NL. Nevertheless, any consideration 
VOL. 29 , NO. 2

TABLE 3

A COMPARISON OF SEVEN VARIABLES WITH REGARD TO TRANSFER ON THE COMBINING TASK

\begin{tabular}{|c|c|c|c|c|c|c|c|}
\hline Variable & & $\overline{\mathbf{x}}$ & sd & $\mathbf{F}$ & bability & values & probability* \\
\hline $\begin{array}{l}\text { Pronoun } \\
\text { retention } \\
\text { subject }\end{array}$ & $\begin{array}{l}\text { Group 1** } \\
\text { Group 2** }\end{array}$ & $\begin{array}{r}14.17 \\
.93\end{array}$ & $\begin{array}{r}26.7 \\
2.8\end{array}$ & 92.37 & .000 & 1.4 & ns \\
\hline $\begin{array}{l}\text { Pronoun } \\
\text { retention } \\
\text { DO }\end{array}$ & $\begin{array}{l}\text { Group 1** } \\
\text { Group 2** }\end{array}$ & $\begin{array}{r}26.46 \\
2.03\end{array}$ & $\begin{array}{l}28.3 \\
4.06\end{array}$ & 48.57 & .000 & 2.42 & .023 \\
\hline $\begin{array}{l}\text { Pronoun } \\
\text { retention } \\
10\end{array}$ & $\begin{array}{l}\text { Group 1** } \\
\text { Group 2** }\end{array}$ & $\begin{array}{r}28.33 \\
7.04\end{array}$ & $\begin{array}{l}29.9 \\
11.2\end{array}$ & 7.1 & .013 & 1.9 & .045 \\
\hline $\begin{array}{l}\text { Pronoun } \\
\text { retention } \\
\text { OPrep }\end{array}$ & $\begin{array}{l}\text { Group 1** } \\
\text { Group 2** }\end{array}$ & $\begin{array}{r}23.13 \\
2.04\end{array}$ & $\begin{array}{l}28.3 \\
4.06\end{array}$ & 48.57 & .000 & 2.09 & .038 \\
\hline $\begin{array}{l}\text { Pronoun } \\
\text { retention } \\
\text { genitive }\end{array}$ & $\begin{array}{l}\text { Group 1** } \\
\text { Group 2**}\end{array}$ & $\begin{array}{l}13.8 \\
16.9\end{array}$ & $\begin{array}{l}20.5 \\
21.5\end{array}$ & 1.1 & ns & -.30 & ns \\
\hline $\begin{array}{l}\text { Pronoun } \\
\text { retention } \\
\text { OComp }\end{array}$ & $\begin{array}{l}\text { Group 1** } \\
\text { Group 2** }\end{array}$ & $\begin{array}{r}30.2 \\
8.7\end{array}$ & $\begin{array}{r}37.8 \\
16.9\end{array}$ & 4.99 & .019 & 1.48 & ns \\
\hline Morpholo & $\begin{array}{l}\text { Group 1*** } \\
\text { gy } \\
\text { Group 2*** }\end{array}$ & .85 & $\begin{array}{l}.81 \\
1.4\end{array}$ & 3.37 & ns & -.13 & ns \\
\hline
\end{tabular}

*onetailed test of significance

* Group 1 = speakers of languages with pronoun retention

Group 2 = speakers of languages without pronoun retention

***Group 1 = speakers of languages with an invariable marker

Group 2 = speakers of languages with a variable marker 
of transfer or language transfer must take into account the type of linguistic knowledge being tested, since the results obtained using different methods of elicitation are likely to differ. This is further supported by arguments in Legum (1978).

The AH was proposed as a language universal. Hence, the predictions made based on it are intended to be valid in all of the world's natural languages. It is proper to consider whether, in addition to its being a language universal, there is any direct evidence that it affects language processing i.e. that it is "psychologically real". Based on reasonable interpretations of accessible, there are at least two possible testing areas of this hypothesis. First, the more accessible positions should be produced with greater frequency than the less accessible ones (i.e. they can be accessed more readily) and second, the more accessible positions should be produced with greater accuracy than the less accessible ones (i.e. they can be accessed with fewer errors). Keenan (1975) and Faber (1977), using data from native speakers of English, and Gass (1979b), using data from adult L2 learners, provided evidence to substantiate the first prediction. With regard to the second prediction, we would hypothesize that correct responses of L2 learners would decrease as one descends the hierarchy. If we consider Figure 1, we see that this second prediction is borne out in the results of the sentence combining task. The easiest position to relativize was subject position with the lower positions becoming more difficult (as is evidenced by the percentage of correct responses), with the genitive as an exception. Since this is true for all language groups tested here, it suggests that the areas of difficulty for these groups can be predicted on the basis of universal properties of RC's rather than on the basis of language specific properties.

As we have seen, the AH represents an ordering of difficulty in $\mathrm{L} 2$ acquisition. However, it is not a rigid constraint which must be followed in all instances. Additional linguistic factors may come into play which can overcome the natural ordering which this hierarchy imposes on learning. As was mentioned above there were more correct responses to the genitive on the SC task than would have been predicted by a consideration of its position on the hierarchy. Therefore, there are certain structural target language features of the genitive which give it increased prominence.

${ }^{7}$ It is, of course, possible to hypothesize that the ordering found in this study argues against the hierarchy proposed by Keenan and Comrie. The fact that the genitive is out of hierarchical order could be construed to be counter- 
Fioure 1.

Percentroe of sentences correct on combining task (all groups)

$N=188$

80

70

60

so

40

30

20

10

$\mathbf{0}$

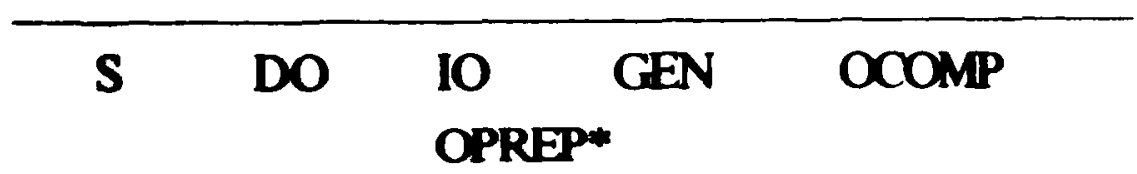

- These two positions have been combined due to their analogous behavior in Endish relative clauses.

Percentage of sentences correct by language groups

S DO 10 GEN OOOMP

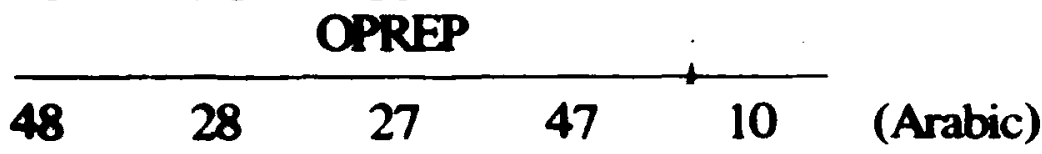

$\begin{array}{llllll}90 & 30 & 25 & 30 & 13 & \text { (Thai) }\end{array}$

$\begin{array}{llllll}68 & 28 & 17 & 33 & 0 & \text { (Romance) }\end{array}$

$\begin{array}{llllll}70 & 20 & 18 & 38 & 4 & \text { (Persian) }\end{array}$

$\begin{array}{llllll}78 & 60 & 28 & 88 & 0 & \text { (Ohinese, Japanese, Korean) }\end{array}$ 
There are two plausible explanations for this. One possibility is that this position has the only relative marker that is uniquely soded for case/grammatical relation in English. Moreover, there are no variants such as that or which which can be used. The fact that whose is uniquely coded and that there are no variants, may serve to make it the most salient of the English relative clause markers, thereby rendering it easily perceivable by the L 2 learner. A second possibility is that the subjects of the present study may have interpreted the genitive marker plus the following noun phrase as a unit which was then treated as a subject or direct object of the verb. For example, in 1 below

1. The man whose son just came home... .

it is possible that whose son was treated as a unit, the subject of the verb came (Jessica Wirth, personal communication). In the corpus of this study all instances of the genitive in this view were either subjects or direct objects, positions high on the hierarchy. This would then explain its relatively high number of correct responses. In summary, despite the universality of the $\mathrm{AH}$ and its active role in $\mathrm{L} 2$ learning, its modification by intralingual features is indeed possible.

\section{Conclusion}

Selinker (1969) investigated some fundamental issues of language transfer including 1) what transfer consists of, 2) what actually is transferred and 3) how language transfer occurs. The present study set out to further our knowledge in this area by extending this list of questions to incorporate an investigation of the role of universals of grammatical relations in language transfer.

In considering the relationship between NL facts and language universals, the latter were found to play the leading role in this study since they were dominant both in assigning relative orders of difficulty and in determining where language transfer occurs. It was further found that when pronoun retention was considered as a class of phenomena, it was not found for all instances. In other words, transfer of a variable was not uniform across the grammar since, in some instances, universals decreased the likelihood of the occurrence of transfer while in others the opposite effect was

evidence to their claim. However, since there is strong independent motivation for the existence of the hierarchy as proposed, it is more explanatory to account for the one exception than to reject this hierarchy. 
noted. This was seen clearly in the case of the $\mathrm{AH}$ for which transfer effects were found in some positions but not in others.

An essential question with regard to language transfer is: what parts of the narive language linguistic system are most likely to be transferred? Phrased in terms of this study, we asked: what linguistic variables are involved in language transfer? Since pronoun retention was the only $R C$ variable for which transfer effects could be determined, it would be interesting to consider how this variable differs from the others investigated. First, the presence of a pronominal copy in a RC corresponds with other similar struc. tures in English. ${ }^{8} \mathrm{~A}$ second differentiating factor is that pronouns are morphologically overt and thus have a certain degree of perceptual salience. Thirdly, the transferred pattern is less elliptical than the TL pattern and as a result appears not to require as sophisticated a perceptual analysis on the part of the learner.

However, our primary concern in this paper is not with this one particular class of examples, but rather with the possibilities for language transfer as a general phenomenon. Therefore, it is proper to discern the essential characteristic responsible for each of the differences cited above. The most salient characteristi of the first distinction is that "surface" features are involved. This is further supported by Broselow (1979) who argues that the analogous characteristic is crucial in instances of phonological transfer. The second difference deals with the "distance" between the relevant structure in the TL and the transferred pattern in the interlanguage. Despite initial attempts in developing a model of language distancel (Wildgen 1977), at present there is nothing precise enough to allow these intuitive remarks to be qualified. Nonetheless, it is clear from the examples in $\mathrm{fn} .8$ that the transferred interlanguage pattern is not distant from English since those examples show instances where pronoun retention in RC's is common in English. Additional support comes from Kellerman (1977. 1979) who argues that language transfer in large part depends on the learner's notion of distance between the native and target languages. In his view, language transfer is more likely to occur in the case where two languages are close. The third difference cited

${ }^{8}$ In the written discourse of science, such that constructions, which have much the same semantic function as RC's, frequently contain pronominal reflexes of the head noun.

a. A string such that a phrase grammar generates it. . .

Additionally, pronaminal copies are frequently used in complex unmonitored oral productions of RC's. 
above is characterized by the closeness of the interlanguage form to the underlying logical structure (cf. Keen:.n 1972 for a discussion of the logical structure of RC's). That is, it must be as close or closer to the semantic representation of the construction under consideration.

Even though we are unable to determine at present which of these factors is dominant and what the interplay between them might be, we hypothesize that these three characteristics are universally valid in predicting language transfer. While there is insufficient evidence to believe that all three factors must be found in each instance of language transfer, we claim that the presence of all three will increase its likelihood.

Clearly, this hypothesis must be systematically tested against a broader range of language data. Nevertheless, it is apparent from this study that the likelihood of the transferability of linguistic phenomena must take into account both target language facts and rules of universal grammar.

\section{REFERENCES}

Broselow, Ellen. 1979. An investigation of transfer in second language phonology. unpublished ms.

Cook, Vivian. 1973. The comparison of language development in native children and foreign adults. IRAL. 11 13-28.

Comrie, Bernard and Edward Keenan. 1979. Noun phrase accessibility revisited. Lg. 55.649-664.

Dulay, Heidi and Marina Burt. 1974. You can't learn without goofing. Error Analysis: Perspectives on Second Language Acquisition, ed. by Jack Richards. London: Longman.

1975. Creative construction in secona language learning and teaching. On TESOL 75: New Directions in Second Language Learning, Teaching and Bilingual Education, ed. by Marina Burt and Heidi Dulay. Washington, D.C.: TESOL.

Faber, Alice. 1977. Distribution of relative clauses in extemporaneous English discourse. Paper presented at LSA, Winter Meeting.

Gass, Susan. 1979a. An investigation of syntactic transfer in adult L2 learners. Research in Second Language Acquisition, ea. by Robin Scarcella and Stephen Krashen. Rowley, Mass.: Newbury House.

1979b. Second language acquisition and language universals. Paper presented at the 1979 Delaware Symposium on Language Studies.

George, H. V. 1972. Common Errors in Language Learning. London: Newbury House. 
Gradman, Harry. 1970. The Contrastive Analysis Hypothesis: What It Is, and What It Isn't. Ph.D. dissertation, Indiana University. 1972. Contrastive paradigms for second language learning: implications for language comparison. Paper presented at the 1 hird International Cognress of Applied Linguistics.

loup, Georgette and Anna Kruse. 1977. Interference versus structural complexity as a predictor of second language relative clause acquisition. Proceedings of the Second Language Research Forum, ed. by Carol Henning. Los Angeles.

Jakobovits, Leon. 1970. Foreign Language Learning. Rowley, Mass.: Newbury House.

James, Juliane. 1977. Language transfer reconsidered. Interlanguage Studies Bulletin 2.7-21.

Keenan, Edward. 1972. On semantically based grammar. Linguistic Inquiry 4.413-461.

. 1975. Variation in universal grammar. Analyzing Variation in Language, ed. by Ralph Fasold and Roger Shuy. Washington, D.C.: Georgetown University Press.

and Bernard Comrie. 1977. Noun phrase accessibility and universal grammar. Linguistic Inquiry 8.63-99.

1979. Data on the noun phrase accessibility hierarchy. Language 55.333-351.

Kellerman, Eric. 1977. Towards a characterization of the strategy of transfer in second language learning. Interlanguage Studies Bulletin 2.58-146.

1979. Transfer and non-transfer: where we are now. Studies in Second Language Acquisition. 2:37-57.

Legum, Stanley. 1978. The relative clause methodological study. Paper presented at LSA Winter Meeting, Boston.

Richards, Jack. 1975. Error analysis and second language strategies. New Frontiers in Second Language Learning, ed. by John Schumann and Nancy Stenson. Rowley, Mass.: Newbury House.

Schachter, Jacqueline. 1974. An error in error analysis. Language Learning. 24.205-214.

Selinker, Larry. 1966. A Psycholinguistic Study of Language Transfer. Ph.D. dissertation. Georgetown University. 1969. Language transfer. General Linguistics 9.67-92.

Wardhaugh, Ronald. 1970. The contrastive analysis hypothesis. TESOL Quarterly 4.123-130.

Wildgen, Wolfgang. 1977. Differentielle Linguistik. Tubingen: Max Niemeyer Verlag. 